\title{
Detection of COPD in a high-risk population: should the diagnostic work-up include bronchodilator reversibility testing?
}

This article was published in the following Dove Press journal:

International Journal of COPD

23 February 2015

Number of times this article has been viewed

Peter Kjeldgaard'

Ronald Dahl ${ }^{2}$

Anders Løkke ${ }^{3}$

Charlotte Suppli Ulrik ${ }^{1,4}$

'Department of Pulmonary Medicine, Hvidovre Hospital, Hvidovre; ${ }^{2}$ Allergy Centre, Odense University Hospital, Odense, ${ }^{3}$ Department of Pulmonary Medicine, Århus Sygehus, Aarhus C; ${ }^{4}$ University of Copenhagen,

Copenhagen, Denmark
Correspondence: Charlotte Suppli Ulrik Department of Pulmonary Medicine 253, Hvidovre Hospital, DK-2650 Hvidovre, Denmark

Email csulrik@dadlnet.dk
Background: Underdiagnosis of chronic obstructive pulmonary disease (COPD) is widespread. Early detection of COPD may improve the outcome by timely smoking cessation, a change in lifestyle, and treatment with an inhaled bronchodilator (BD). The objective of this study was to evaluate the diagnostic role of BD reversibility testing in early COPD case finding.

Methods: General practitioners $(n=241)$ consecutively recruited subjects aged $\geq 35$ years with relevant exposure (history of smoking, and/or occupational exposure) and at least one respiratory symptom. Information on age, smoking status, body mass index, dyspnea score (Medical Research Council scale), and spirometry was obtained. Individuals with airway obstruction (forced expiratory volume in one second $\left[\mathrm{FEV}_{1}\right] /$ forced vital capacity $[\mathrm{FVC}]<0.70$ ) underwent a BD test with an inhaled $\beta_{2}$ agonist, which was considered positive if $\Delta F E V_{1}$ was $>0.20 \mathrm{~L}$ and $>12 \%$. Asthma and COPD were, respectively, defined as an $\mathrm{FEV}_{1}$ increase $>0.50 \mathrm{~L}$ and a post-BD $\mathrm{FEV}_{1} / \mathrm{FVC}<0.70$.

Results: In total, 4,049 subjects (51\% male) were included (mean age 58 years, body mass index 27, 32 pack-years of smoking). A significant BD response was found in $143(15 \%)$ of the 937 subjects (23\%) with airway obstruction at screening spirometry. In 59\% of these subjects, the post-BD $\mathrm{FEV}_{1} / \mathrm{FVC}$ remained $<0.70$. In $24 \%$ of the subjects with pre-BD airway obstruction, the post-BD $\mathrm{FEV}_{1} / \mathrm{FVC}$ ratio was within the reference range. In subjects with confirmed $\mathrm{COPD}$, the mean increase in $\mathrm{FEV}$, following BD was $0.11 \mathrm{~L} \pm 0.10 \mathrm{~L}$. The subjects with COPD and a significant $\mathrm{BD}$ response were characterized by a higher prevalence of dyspnea $(72 \%$ versus $57 \%, P=0.02)$ but less cough $(55 \%$ versus $75 \%, P=0.001)$ when compared with COPD subjects without $\mathrm{BD}$ reversibility.

Conclusion: Administration of a BD in COPD case finding is important in order to determine the post-BD $\mathrm{FEV}_{1} / \mathrm{FVC}$ ratio. Exclusion of subjects with a significant $\mathrm{BD}$ response may result in underdiagnosis of COPD, and we question the need for the BD reversibility test in the diagnostic screening algorithm in early COPD case finding.

Keywords: chronic obstructive pulmonary disease, screening, reversibility, diagnosis, spirometry

\section{Introduction}

Chronic obstructive pulmonary disease (COPD) is a common disease, and it has been estimated that 23 million people in Europe are living with COPD stage II-IV and that 17 million have stage I disease. ${ }^{1}$ The annual cost of COPD in Europe, including health care costs, has been estimated to be 141 billion Euros. Furthermore, the prevalence of the disease is predicted to increase until at least $2030 .{ }^{1}$

Secondary prevention is one way to address the increase in morbidity and health care expenses, and brings the importance of early detection of COPD into focus. 
The symptoms of COPD are often acknowledged at a time when significant disease and loss of lung function has occurred and the consequence is therefore late diagnosis. Studies suggest that, on spirometric screening of high-risk populations, $19 \%-24 \%$ of the screened population will be diagnosed with COPD and a significant proportion will have mild to moderate airflow limitation..$^{2-4}$

A subgroup analysis of the UPLIFT and TORCH studies, as well as a study by Tantucci et $\mathrm{al}^{5}$ show that the decline in lung function occurs faster in the earlier stages of the disease..$^{5-7}$ Therefore, early diagnosis may provide the opportunity to prevent further deterioration in lung function, primarily by addressing exposure to inhaled noxious particles and gases, including smoking, physical activity, and possibly also to initiate pharmacological intervention.

Recommendations and diagnostic work-up for early case finding of COPD remain to be established. In some studies, a bronchodilator (BD) reversibility test (using a short-acting $\beta_{2}$-agonist) has been performed as part of the diagnostic work-up in an attempt to distinguish between subjects with COPD and those with asthma. ${ }^{8-12}$ However, the value of the $\mathrm{BD}$ reversibility test as a diagnostic tool has been much debated because the presence of a significant BD response is an overlapping feature of COPD and asthma. ${ }^{1}$ In 2006, national recommendations for early detection of COPD in general practice in Denmark were implemented by the Danish National Board of Health. Based on these recommendations, a large study was conducted to evaluate the diagnostic yield, prevalence, and severity of COPD by following these recommendations in a large cohort of individuals recruited through a representative sample of Danish general practitioners (GPs; the TOP GOLD study). ${ }^{2}$ As part of the study, data were obtained on spirometric findings and reversibility to a $\beta_{2}$-agonist (and corticosteroids in some cases).

The objective of the present analysis of data from that study was to assess the diagnostic value of the BD reversibility test in early case finding of COPD in a high-risk population identified in general practice.

\section{Materials and methods}

\section{Study design}

GPs throughout Denmark were invited to take part in this study and the aim was to engage at least 200 GPs $(>5 \%$ of Danish GPs) in order to obtain a representative sample. ${ }^{2}$ Each of the participating GPs was expected to assess at least 20 consecutive subjects who attended their practice and fulfilled the criteria for participation in the study (6-month study period). Subjects included had all study-related procedures performed in their own GP's surgery.

\section{Materials}

Subjects were eligible for the study provided they fulfilled the inclusion criteria (age $\geq 35$ years, smoker/ex-smoker or relevant occupational exposure, and at least one respiratory symptom [dyspnea, cough, wheeze, sputum, and/or recurrent chest infections]) and had no exclusion criteria (unable to perform spirometry, previous diagnosis of obstructive lung disease).

\section{Methods}

All participants filled in a questionnaire regarding age, sex, height, body weight, smoking status (including daily tobacco consumption and years of smoking), airway symptoms (including cough, dyspnea, wheezing, sputum, and recurrent lower airway infections), and severity of dyspnea (Medical Research Council scale). ${ }^{13}$ Spirometry was performed in accordance with the guidelines of the Danish Respiratory Society, ${ }^{14}$ and included at least three forced expiratory maneuvers (and at least two measurements of forced expiratory volume in one second $\left[\mathrm{FEV}_{1}\right]$ and forced vital capacity [FVC], respectively, differing by less than 5\%). European Community for Steel and Coal reference values for lung function was used. ${ }^{15}$

\section{Diagnostic algorithm}

Airway obstruction was defined as an $\mathrm{FEV}_{1} / \mathrm{FVC}$ ratio $<0.70$, in accordance with the Global Initiative for Chronic Obstructive Lung Disease (GOLD) strategy document. ${ }^{16}$ All participants with a $\mathrm{FEV}_{1} / \mathrm{FVC}$ ratio $<0.70$ at screening spirometry (ie, pre-BD spirometry) had a BD reversibility test performed with $0.4 \mathrm{mg}$ of inhaled salbutamol (or equivalent) followed by spirometry 15 minutes later; further details are given in Figure 1 (CONSORT diagram). Those with $\triangle \mathrm{FEV}_{1}$ of $0.200-0.500 \mathrm{~L}$ was further tested with a corticosteroid reversibility test performed with either inhaled budesonide $1,600 \mu \mathrm{g}$ daily (or equivalent) for 6 weeks or oral prednisolone $37.5 \mathrm{mg}$ daily for 10 days (further details in the diagnostic algorithm). ${ }^{17}$

\section{Data handling and analysis}

The results of the questionnaire and the spirometric data were recorded in a consolidated web-based database. Derived values were automatically calculated by the computer, including number of pack-years, body mass index (BMI), $\mathrm{FEV}_{1} \%$ predicted, $\mathrm{FEV}_{1} / \mathrm{FVC}$, and COPD severity based 


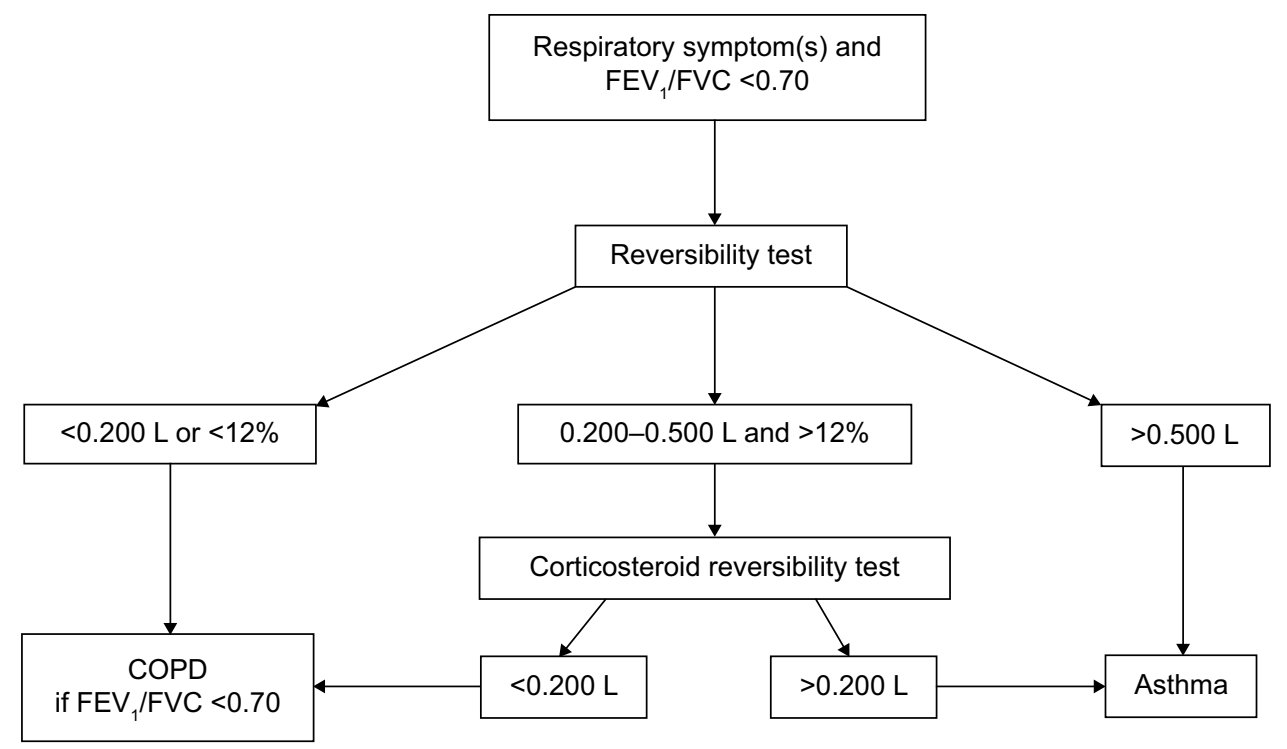

Figure I Flowchart describing the diagnostic algorithm used for participants with a screening spirometry revealing airflow obstruction (FEV $/$ FVC $<0.70$ ). Abbreviations: COPD, chronic obstructive pulmonary disease; $\mathrm{FEV}_{1}$, forced expiratory volume in one second; FVC, forced vital capacity.

on $\mathrm{FEV}_{1} \%$ predicted. Statistical analyses were performed using Statistical Package for the Social Sciences version 21.0 software (IBM Corporation, Armonk, NY, USA) with assistance from the Statistics Department, Clinical Research Centre, Hvidovre University Hospital, Denmark.

The analyses were limited to subjects with complete data. The data were tested for normality, and nonparametric tests for independent samples were used to analyze continuous data. Categorical data were analyzed using the Mann-Whitney $U$-test. In all the statistical analyses, a two-tailed $P$-value of $\leq 0.05$ was considered to be statistically significant. Mean values are reported with standard deviations. To test for outliers, the actual change in $\mathrm{FEV}_{1}$ following administration of $\mathrm{BD}$ was visualized by a dot plot, and data for individuals with a change of $>1.0 \mathrm{~L}$ were excluded from the analyses. Negative values were excluded when calculating the mean $\mathrm{FEV}_{1}$ response to the reversibility test in order to describe the positive responders. Groups of interest were compared based on the presence of airway obstruction at screening spirometry, COPD, and BD reversibility. In the analyses, subjects were included in the "no COPD" group based on the following criteria: $\mathrm{FEV}_{1} / \mathrm{FVC}$ $\geq 0.70$ at screening spirometry or post-BD $\mathrm{FEV}_{1} / \mathrm{FVC} \geq 0.70$, a $\mathrm{BD}$ reversibility test with an increase in $\mathrm{FEV}_{1}>0.500 \mathrm{~L}$, or a positive corticosteroid reversibility test.

\section{Ethics statement}

The present study was endorsed by the Danish College of General Practitioners. According to the European Federation of Pharmaceutical Industries and Associations code and the Danish Association of the Pharmaceutical Industry, the present study was a nondrug, noninterventional study, and approval from the scientific ethics committee and the Danish Medicines Agency were not mandatory, but they were given all relevant study information. The study was approved by the Danish Data Protection Agency.

\section{Results \\ Characteristics of enrolled subjects}

In total, 241 GPs (approximately 7\% of all Danish GPs) participated in the study, and 4,049 subjects (51\% male) with a mean age of 58 (range 35-91) years had complete data, so were included in the analyses. Fifty-nine percent of subjects were current smokers ( $48 \%$ males and $60 \%$ females), and $4 \%$ declared themselves as having never smoked. Mean estimated lifetime tobacco exposure among never, current, and former smokers was 37 (range 0-193) pack-years in men and 27 (range 0-168) pack-years in women.

\section{Prevalence of airway obstruction at screening spirometry}

In total, 937 (23\%) of the 4,049 subjects had airway obstruction at screening, ie, an $\mathrm{FEV}_{1} / \mathrm{FVC}$ ratio $<0.70$ at the screening spirometry. The mean $\mathrm{FEV}_{1} / \mathrm{FVC}$ ratio was $0.61 \pm 0.08$ in subjects with airway obstruction compared with $0.79 \pm 0.06$ in the remaining enrolled subjects. The mean $\mathrm{FEV}_{1}$ was $2.0 \mathrm{~L} \pm 0.7 \mathrm{~L}$ compared with $2.8 \mathrm{~L} \pm 0.8 \mathrm{~L}$ in the subjects without airway obstruction and $\mathrm{FEV}_{1} \%$ predicted was $70 \%$ and $93 \%$, respectively. 


\section{Prevalence of COPD}

Of the 4,049 subjects screened, 716 (18\%) had a post-BD $\mathrm{FEV}_{1} / \mathrm{FVC}$ ratio $<0.70$. Twenty-three of these subjects had a post-BD increase in $\mathrm{FEV}_{1}>0.500 \mathrm{~L}$, and six subjects had a positive corticosteroid reversibility test. Thus, the criteria for diagnosis of COPD were met in 687 subjects (17\%). Of the subjects with airway obstruction at screening spirometry, $74 \%$ were diagnosed as having COPD and $2.5 \%$ as having asthma, whereas $23.5 \%$ had reversal of airway obstruction without fulfilling the criteria for asthma. Most subjects had mild to moderate disease (GOLD I, 31\%; GOLD II, 53\%) according to the GOLD classification of severity of airflow limitation $^{16}$ (see Supplementary materials section). The mean $\mathrm{FEV}_{1}$ was $1.9 \mathrm{~L}_{\text {in }}$ subjects diagnosed with COPD compared with $2.8 \mathrm{~L}$ in subjects who did not meet the criteria for COPD. Subjected diagnosed with COPD were on average 7 years older and had 10 pack-years more tobacco exposure compared with those without COPD (Table 1). Subjects who met the criteria for diagnosis of COPD also had a significantly higher prevalence of dyspnea, wheezing, sputum, and self-reported recurrent respiratory infections. The BMI was almost the same in the two groups (Table 1 and Figure 2).

\section{Prevalence and characteristics of BD reversibility}

The majority ( $88 \%$ ) of the individuals had the BD reversibility test performed on the same day as the screening spirometry. Of

Table I Characteristics of enrolled subjects with a confirmed diagnosis of COPD (ie, post-bronchodilator FEV $/$ FVC <0.70) versus subjects not having COPD

\begin{tabular}{|c|c|c|c|}
\hline & $\begin{array}{l}\text { COPD } \\
(n=687)\end{array}$ & $\begin{array}{l}\text { No COPD } \\
(n=3,362)\end{array}$ & $P$-value \\
\hline Sex, male & 369 (54\%) & $\mathrm{I}, 688(50 \%)$ & 0.094 \\
\hline Age & $63(10.5)$ & $56(11.8)$ & $<0.001$ \\
\hline $\mathrm{BMI}$ & $26(5.1)$ & $27(5.1)$ & $<0.001$ \\
\hline Pack-years & $40(23.2)$ & $30(21.9)$ & $<0.001$ \\
\hline \multicolumn{4}{|l|}{ Symptoms } \\
\hline Cough & $50 \mathrm{I}(73 \%)$ & 2,389 (71\%) & 0.324 \\
\hline Dyspnea & $398(58 \%)$ & I,554 (46\%) & $<0.001$ \\
\hline Wheezing & $183(27 \%)$ & $559(17 \%)$ & $<0.001$ \\
\hline Sputum & 281 (4I\%) & $963(29 \%)$ & $<0.001$ \\
\hline Recurrent RTI & $88(13 \%)$ & $28(10 \%)$ & 0.016 \\
\hline MRC & $2(0.8)$ & $1.7(0.7)$ & $<0.001$ \\
\hline \multicolumn{4}{|l|}{ Spirometry } \\
\hline FEV, screening & $1.9(0.69)$ & $2.8(0.83)$ & $<0.001$ \\
\hline $\mathrm{FEV}, \%$ predicted ${ }^{\mathrm{c}}$ & $68(19.4)$ & $92(18.2)$ & $<0.00$ I \\
\hline
\end{tabular}

Notes: Data are given as the mean \pm standard deviation or number of subjects (\%). aSubjects with $\mathrm{FEV}, / \mathrm{FVC} \geq 0.70$ or post-bronchodilator $\triangle \mathrm{FEV},>0.500 \mathrm{~L}$; ${ }^{\mathrm{b}} \mathrm{FEV}$, at initial screening spirometry; ${ }^{\mathrm{C} F E V}, \%$ predicted.

Abbreviations: BMI, body mass index; COPD, chronic obstructive pulmonary disease; $\mathrm{FEV}_{1}$, forced expiratory volume in one second; FVC, forced vital capacity; MRC, Medical Research Council dyspnea scale; RTI, respiratory tract infection.

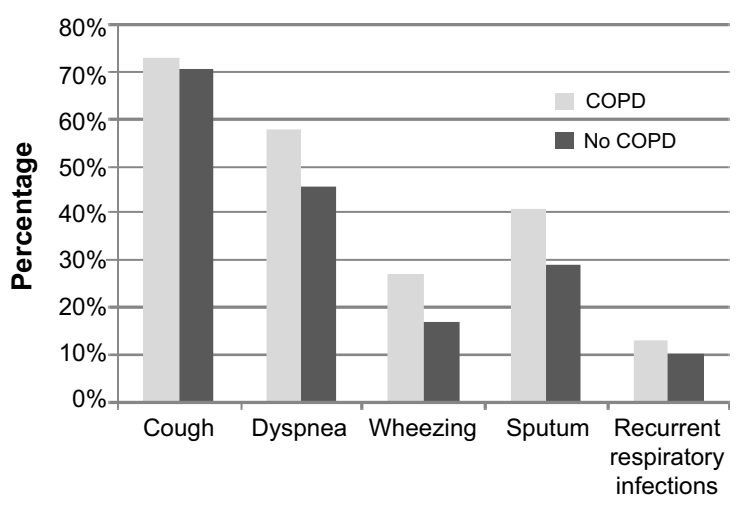

Figure 2 Prevalence of respiratory symptoms in individuals diagnosed with COPD compared with individuals not fulfilling the spirometric criteria for a diagnosis of COPD.

Note: All enrolled subjects had more than one respiratory symptom.

Abbreviation: COPD, chronic obstructive pulmonary disease.

the 937 subjects who had airway obstruction at screening spirometry, a significant BD response was found in 143 (15\%). Considerable overlap was found between the presence of a significant $\mathrm{BD}$ response and the presence of airway obstruction $\left(\mathrm{FEV}_{1} / \mathrm{FVC}\right.$ $<0.70$, Figure 3). In $59 \%$ of the subjects who had a significant $\mathrm{BD}$ response, the post-BD ratio remained at $<0.70$. This group had a higher mean change in FVC $(0.52 \mathrm{~L} \pm 0.06 \mathrm{~L})$ compared with the mean change in $\mathrm{FEV}_{1}(0.42 \mathrm{~L} \pm 0.02 \mathrm{~L})$. The mean pre-BD $\mathrm{FEV}_{1} / \mathrm{FVC}$ ratio was $0.56 \pm 0.009$.

A total of $221(24 \%)$ subjects with airway obstruction $\left(\mathrm{FEV}_{1} / \mathrm{FVC}\right.$ ratio $\left.<0.70\right)$ at screening spirometry had no airway obstruction following administration of a BD. Of the 937 subjects tested for BD reversibility, 23 (3\%) had an increase in $\mathrm{FEV}_{1}$ of $>0.500 \mathrm{~L}$ in spite of a post-BD $\mathrm{FEV}_{1} /$ FVC ratio of $<0.70$.

In participants which met the criteria for diagnosis of COPD, the post-BD increase in $\mathrm{FEV}_{1}$ was $0.11 \mathrm{~L} \pm 0.10 \mathrm{~L}$ and

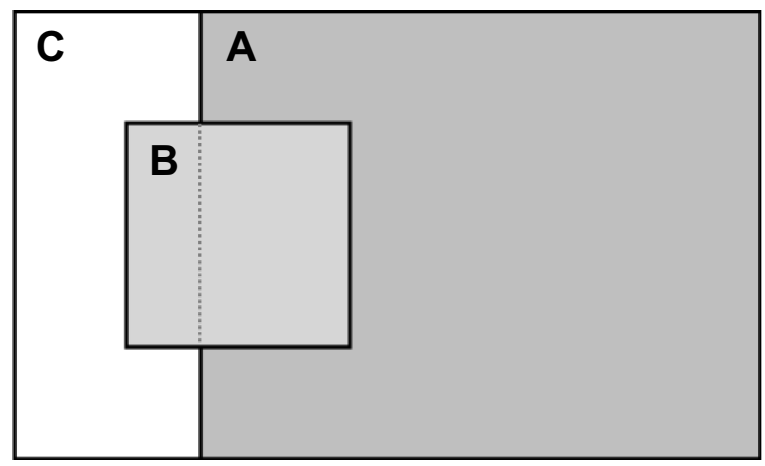

Figure 3 Graphic representation of all subjects with airway obstruction a at screening spirometry $(n=937)$ according to the presence of post-bronchodilator airway obstruction and/or BD reversibility.

Notes: (A) Subjects with post-BD airway obstruction, (B) subjects with a significant $\mathrm{BD}$ response, and $(\mathbf{C})$ subjects with normal post-BD $\mathrm{FEV} / \mathrm{FVC}$. ${ }^{\mathrm{a} F E V_{1} / \mathrm{FVC} \text { ratio }}$ $<0.70$; ${ }^{\text {bchange in } \mathrm{FEV}},>0.200 \mathrm{~L}$ and $>12 \%$.

Abbreviations: $\mathrm{BD}$, bronchodilator; $\mathrm{FEV}_{1}$, forced expiratory volume in one second; FVC, forced vital capacity. 
in $70 \%$ of the subjects the increase in $\mathrm{FEV}_{1}$ was $<0.20 \mathrm{~L}$. Overall, the mean post-BD increase in $\mathrm{FEV}_{1}$ of the subjects with airway obstruction at screening spirometry was $0.15 \pm 0.16 \mathrm{~L}$. A total of 637 (68\%) subjects had a positive BD response large enough to meet the cut-off criteria. A negative (ie, decline) change in $\mathrm{FEV}_{1}$ occurred in 157 (17\%) of the tested subjects.

In 78 of the cases with a diagnosis of COPD, the severity of airflow limitation according to the GOLD classification was one step lower, and for one subject two steps lower, after the BD reversibility test. No difference was found between BD response and smoking status, pack-years, or age (Table 2).

Nine percent of subjects who met the criteria for diagnosis of COPD had a positive BD reversibility test, and these patients were characterized by a higher occurrence of dyspnea (72\% versus $57 \%, P=0.024$ ), whereas cough was reported less frequently $(55 \%$ versus $75 \%, P=0.001)$ than in subjects without BD reversibility. There were no difference in BMI between the compared groups (Table 2).

\section{Prevalence of reversibility to corticosteroids}

A total of 128 subjects were tested further with corticosteroids due to an increase in $\mathrm{FEV}_{1}$ of $0.200-0.500 \mathrm{~L}$ on the BD reversibility test. Six subjects had a positive corticosteroid test (ie, a further increase in $\mathrm{FEV}_{1}$ of $>0.200 \mathrm{~L}$ ).

Table 2 Comparison of characteristics for subjects with a confirmed diagnosis of COPD (ie, post-bronchodilator FEV,/FVC $<0.70$ ) with and without bronchodilator reversibility

\begin{tabular}{|c|c|c|c|}
\hline & $\begin{array}{l}\text { Reversibility } \\
(n=60)\end{array}$ & $\begin{array}{l}\text { No reversibility } \\
(n=627)\end{array}$ & P-value \\
\hline Sex, male & 35 (58\%) & 334 (52\%) & 0.452 \\
\hline Age & $63(10.0)$ & $63(10.5)$ & 0.407 \\
\hline $\mathrm{BMI}$ & $26(5.7)$ & $26(5.0)$ & 0.531 \\
\hline Pack-years & $42(23.5)$ & $40(23.2)$ & 0.380 \\
\hline \multicolumn{4}{|l|}{ Symptoms } \\
\hline Cough & 33 (55\%) & 468 (75\%) & 0.001 \\
\hline Dyspnea & $43(72 \%)$ & $355(57 \%)$ & 0.024 \\
\hline Wheezing & $16(27 \%)$ & $167(27 \%)$ & 0.996 \\
\hline Sputum & 25 (42\%) & 256 (4I\%) & 0.900 \\
\hline Recurrent RTI & $10(17 \%)$ & 78 (I2\%) & 0.349 \\
\hline $\mathrm{MRC}$ & $2.2(0.8)$ & $2.0(0.8)$ & 0.152 \\
\hline \multicolumn{4}{|l|}{ Spirometry } \\
\hline FEV, screening ${ }^{\mathrm{a}}$ & $\mathrm{I} .7(0.6)$ & $1.9(0.7)$ & 0.014 \\
\hline $\mathrm{FEV}_{1} \%$ predicted $^{\mathrm{b}}$ & $58(13.4)$ & $68(19.6)$ & $<0.001$ \\
\hline
\end{tabular}

Notes: Data are given as the mean (standard deviation) or number (\%) of subjects; a positive reversibility test defined as $\Delta \mathrm{FEV},>0.200 \mathrm{~L}$ and $\mathrm{I} 2 \%$ of pre-bronchodilator $\mathrm{FEV}$, level after administration of bronchodilator; ${ }^{\mathrm{a}} \mathrm{FEV}$, at initial screening spirometry; ${ }^{\circ} \mathrm{FEV}, \%$ predicted.

Abbreviations: BMI, body mass index; COPD, chronic obstructive pulmonary disease; $\mathrm{FEV}_{1}$, forced expiratory volume in one second; FVC, forced vital capacity; MRC, Medical Research Council dyspnea scale; RTI, respiratory tract infection.

\section{Discussion}

The present study of early COPD case finding is by far the largest conducted study, with spirometric data from 4,049 screened subjects at high risk of COPD; moreover, the inclusion of 241 GPs across Denmark ensured a representative nationwide sample.

In the study, it was revealed that approximately one quarter of the population at risk of COPD had airway obstruction when screened with spirometry. However, a quarter of these subjects with airway obstruction had an $\mathrm{FEV}_{1} / \mathrm{FVC}$ ratio within the reference range following administration of a BD, so did not meet the GOLD criteria for COPD. The post-BD ratio remained at $<0.70$ in the majority of the subjects who had a significant $\mathrm{BD}$ response.

The criteria for a diagnosis of COPD was met in 17\% of the 4,049 included subjects, and in accordance with other studies of early COPD case finding, the severity of airflow obstruction was primarily mild to moderate (GOLD I, 31\%; GOLD II, 53\%). ${ }^{2-4}$ These results suggest that, in a defined population at risk of COPD who attend their GP for any reason, a substantial proportion can be diagnosed with the disease by an early case finding strategy.

The rationale for early case finding of COPD is supported by recent systematic reviews of the published literature concerning mild to moderate COPD, which favors early intervention. ${ }^{18,19}$ In line with this, BD therapy in relatively mild COPD, as assessed by spirometric criteria, can improve dyspnea and lung function. $6,16,20$

To our knowledge, the present study is the first to address the role of the BD reversibility test in early case finding of COPD as the primary objective; other studies of COPD case finding have mainly examined different screening tests, eg, simple spirometry $\left(\mathrm{FEV}_{1} / \mathrm{FVC}, \mathrm{FEV}_{1} / \mathrm{FEV}_{6}\right)$ or peak flow measurement and addressed the diagnostic yield. . $^{3,8-12,21-25}$

A prevalence of COPD in 17\% of the screened population is lower than in other case finding studies, where a frequency of $20 \%-35 \%$ has been found..$^{3,8-12,21-26}$ The proportion of individuals with COPD in a screened population at risk is dependent on both the criteria chosen to define "at risk", as shown by Dirven et $\mathrm{al}^{10}$ and on applied diagnostic criteria for COPD. This was seen in the studies by Ulrik et $\mathrm{al}^{26}$ Vandevoorde et $\mathrm{al}^{25}$ Frith et $\mathrm{al}^{9}$ and Stratelis et $\mathrm{al}^{12}$ where the highest frequencies of COPD were found. The two first studies used the pre-BD FEV $/$ FVC to define airway obstruction, the second only included subjects aged older than 50 years, and the last one used the old 1995 criteria for COPD published by the European Respiratory Society. ${ }^{27}$ Jordan et $\mathrm{al}^{23}$ found a prevalence of COPD of only $5 \%$, explained by their selection criteria (ever-smokers, age $\geq 30$ years) and 
a tight definition of COPD (airway obstruction and symptoms, and $\mathrm{FEV}_{1}<80 \%$ ). Except for the study by Jordan et $\mathrm{al}^{23}$ the present study had the lowest inclusion age ( $\geq 35$ years), which is likely to explain the relatively low prevalence of COPD.

Subjects with COPD had a significant worse dyspnea grade and more wheezing, sputum, and recurrent respiratory infections compared with subjects without COPD. The differences were modest, partly because the presence of at least one respiratory symptom was an inclusion criterion in the present study. The age was higher in the COPD group, which reflects the increasing prevalence in the elderly population. Overdiagnosis by use of a fixed $\mathrm{FEV}_{1} / \mathrm{FVC}$ ratio might in part have contributed to the difference.

In five further studies of COPD case finding (Frith et al, ${ }^{9}$ Thorn et al, ${ }^{8}$ Stratelis et al, ${ }^{12}$ Canals et al, ${ }^{11}$ and Dirven et $\mathrm{al}^{10}$ ), a BD reversibility test was part of the diagnostic workup. BD reversibility in $9 \%$ of subjects with COPD as observed in the present study is high compared with some of the other studies. ${ }^{9,10}$ The comparison is complicated by differences in the definition of reversibility and perhaps also by the type and dose of BD. Frith et $\mathrm{al}^{9}$ and Canals et $\mathrm{al}^{11}$ had a definition of reversibility similar to that in the present study and reported an occurrence of $3 \%$ and $10 \%$, respectively. In the studies with a different definition of reversibility, ie, Dirven et $\mathrm{al}^{10}$ $\left(\Delta \mathrm{FEV}_{1} \geq 12 \%\right)$ and Thorn et $\mathrm{al}^{8}\left(\Delta \mathrm{FEV}_{1}>0.400 \mathrm{~L}\right)$, the occurrence of reversibility was $4.4 \%$ and $4 \%$, respectively. The study reported by Stratelis et al ${ }^{12}$ did not specify the definition of reversibility. The occurrence of $\mathrm{BD}$ reversibility in the general COPD population has been described in several studies. ${ }^{28-31}$ A recent study of patients with COPD from the UPLIFT study found BD reversibility in $52 \%$ of patients using the same criteria for BD reversibility as those used in the present study. ${ }^{32}$

In $59 \%$ of the subjects in the present study who had a significant $\mathrm{BD}$ response, the post- $\mathrm{BD} \mathrm{FEV}_{1} / \mathrm{FVC}$ ratio remained at $<0.70$. This is explained by a larger increase in FVC relative to the change in $\mathrm{FEV}_{1}$ and for some participants a low pre-BD $\mathrm{FEV}_{1} / \mathrm{FVC}$ ratio. If the diagnosis of COPD is based on an algorithm that excludes all subjects with a significant $\mathrm{BD}$ response, there may be a substantial risk of underdiagnosis. The GOLD strategy document does not recommend use of a BD reversibility test in the diagnostic work-up of COPD. ${ }^{16}$ However, this is not the case for the diagnosis of asthma, with the Global Initiative for Asthma (GINA) strategy document recommending a BD reversibility test if asthma is suspected. ${ }^{33}$ Still, it is recognized by the GINA guidelines that $\mathrm{BD}$ reversibility is a common feature of COPD.
The positive predictive value of the $\mathrm{BD}$ reversibility test is suspected to be low in COPD case finding where the population is selected based on risk factors for COPD. Thus, whether the BD reversibility test is necessary in early COPD case finding has to be considered. An alternative case finding model may be to administer a BD to all subjects identified with risk factors for COPD, and simply address whether the post-BD FEV ${ }_{1} / \mathrm{FVC}$ ratio is $<0.70$. The BD reversibility test can then be performed in post-screening assessment in cases where the suspicion of asthma justifies its use.

The diagnostic screening algorithm in early COPD case finding can select subjects with a high likelihood of COPD, but is not diagnostic in itself. The diagnosis of COPD should always be confirmed post-screening by careful individual clinical assessment.

Illustrated by recent publications on the overlap between asthma and COPD, ${ }^{33}$ the diagnostic differentiation between asthma and COPD is not a simple matter of reversibility of airway obstruction by a BD. This is emphasized by several studies in which a significant BD response was found in a considerable proportion of patients with COPD. ${ }^{30,34}$

A limitation of the present study is that the diagnosis of "confirmed" COPD is not based on thorough clinical assessment. Subjects may have had airway obstruction caused by a disease other than COPD, although the occurrence of non-COPD chronic airflow limitation is very low compared with the prevalence of COPD. The occurrence of asthma, which is regarded predominantly as a disease of children and younger subjects, would be expected to be low in the present study population based on the selection criteria (age $\geq 35$ years and no prior obstructive lung disease). Due to the study design, which primarily relies on spirometric tests, it was not possible to differentiate COPD, late onset asthma, or asthma-COPD overlap syndrome.

The study does not account for temporal variation in individual BD response or presence of airway obstruction, which has been demonstrated in studies with repeat testing. ${ }^{30,31,35}$ There are no studies of the correlation between the case finding diagnosis of COPD and the final diagnosis after full clinical assessment.

In conclusion, a substantial proportion of subjects with pre-BD airway obstruction did not have COPD according to GOLD spirometric criteria based on their post-BD $\mathrm{FEV}_{1} /$ FVC ratio. Underdiagnosis of COPD may be a consequence if subjects are excluded based on a significant response in $\mathrm{FEV}_{1}$ on the BD reversibility test. We question whether the BD reversibility test is a necessary part of the algorithm for the initial diagnostic screening in early COPD case finding. 


\section{Acknowledgment}

The authors thank Liane Plauborg (Boehringer Ingelheim) and Jens Dollerup (Pfizer) for their excellent collaboration during the TOP GOLD study.

\section{Disclosure}

This study was sponsored by Boehringer Ingelheim, Denmark, and Pfizer, Denmark. The authors report no other conflicts of interest in this work.

\section{References}

1. European Respiratory Society. European Lung White Book. 2013. Available from: www.erswhitebook.org. Accessed January 12, 2015.

2. Lokke A, Ulrik CS, Dahl R, et al. Detection of previously undiagnosed cases of COPD in a high-risk population identified in general practice. COPD. 2012;9(5):458-465.

3. Tinkelman DG, Price D, Nordyke RJ, Halbert RJ. COPD screening efforts in primary care: what is the yield? Prim Care Respir J. 2007; 16(1):41-48

4. Zieliñski J, Bednarek M; Know the Age of Your Lung Study Group. Early detection of COPD in a high-risk population using spirometric screening. Chest. 2001;119(3):731-736.

5. Tantucci $\mathrm{C}$, Modina D. FEV decline in COPD patients according to severity stages. Am J Respir Crit Care Med. 2008;177:A401.

6. Decramer M, Celli B, Kesten S, et al. Effect of tiotropium on outcomes in patients with moderate chronic obstructive pulmonary disease (UPLIFT): a prespecified subgroup analysis of a randomised controlled trial. Lancet. 2009;374(9696):1171-1178.

7. Jenkins CR, Jones PW, Calverley PM, et al. Efficacy of salmeterol/ fluticasone propionate by GOLD stage of chronic obstructive pulmonary disease: analysis from the randomised, placebo-controlled TORCH study. Respir Res. 2009;10:59.

8. Thorn J, Tilling B, Lisspers K, Jörgensen L, Stenling A, Stratelis G. Improved prediction of COPD in at-risk patients using lung function pre-screening in primary care: a real-life study and cost-effectiveness analysis. Prim Care Respir J. 2012;21(2):159-166.

9. Frith P, Crockett A, Beilby J. Simplified COPD screening: validation of the PiKo-6(R) in primary care. Prim Care Respir J. 2011;20(2): 190-198.

10. Dirven JA, Muris JW, van Schayck CP. COPD screening in general practice using a telephone questionnaire. COPD. 2010;7(5):352-359.

11. Canals-Borrajo G, Martínez-Andión B, Cigüenza-Fuster ML. Spirometry for detection of undiagnosed chronic obstructive pulmonary disease in primary care. Eur J Gen Pract. 2010;16(4):215-221.

12. Stratelis, G, Jakobsson P, Molstad S, Zetterstrom O. Early detection of COPD in primary care: screening by invitation of smokers aged 40 to 55 years. Br J Gen Pract. 2004;54(500):201-206.

13. Bestall JC, Paul EA, Garrod R, Garnham R, Jones PW, Wedzicha JA. Usefulness of the Medical Research Council (MRC) dyspnoea scale as a measure of disability in patients with chronic obstructive pulmonary disease. Thorax. 1999;54(7):581-586.

14. Madsen F, Maltbæk N, Mortensen J, Pedersen OF. Lungefunktionsstandard. Danish Society of Respiratory Medicine, 2007.

15. Quanjer PH, Tammeling GJ, Cotes JE, Pedersen OF, Peslin R, Yernault JC. Lung volumes and forced ventilatory flows. Report Working Party Standardization of Lung Function Tests, European Community for Steel and Coal. Official Statement of the European Respiratory Society. Eur Respir J Suppl. 1993;16:5-40.
16. Global Initiative for Chronic Obstructive Lung Disease. Global Strategy for Diagnosis, Management and Prevention of COPD. 2014. Available from: www.goldcopd.com. Accessed January 12, 2015.

17. Danish Society of Respiratory Medicine. [Guidelines for diagnosis of asthma 2010]. Available from: www.lungemedicin.dk. Accessed January $12,2015$.

18. Maltais, F, Dennis N, Chan CK. Rationale for earlier treatment in COPD: a systematic review of published literature in mild-to-moderate COPD. COPD. 2013;10(1):79-103.

19. Román-Rodríguez M. Early treatment benefits in chronic obstructive pulmonary disease. Hot Topics in Respiratory Medicine. 2010;14:19-26.

20. Johansson G, Lindberg A, Romberg K, Nordström L, Gerken F, Roquet A. Bronchodilator efficacy of tiotropium in patients with mild to moderate COPD. Prim Care Respir J. 2008;17(3):169-175.

21. Laniado-Laborin R, Rendón A, Bauerle O. Chronic obstructive pulmonary disease case finding in Mexico in an at-risk population. Int $J$ Tuberc Lung Dis. 2011;15(6):818-823.

22. Hill K, Hodder R, Blouin M, Heels-Ansdell D, Guyatt G, Goldstein R. Identifying adults at risk of COPD who need confirmatory spirometry in primary care: do symptom-based questions help? Can Fam Physician. 2011;57(2):e51-e57.

23. Jordan RE, Lam KB, Cheng KK, et al. Case finding for chronic obstructive pulmonary disease: a model for optimising a targeted approach Thorax. 2010;65(6):492-498.

24. Castillo D, Guayta R, Giner J, et al. COPD case finding by spirometry in high-risk customers of urban community pharmacies: a pilot study. Respir Med. 2009;103(6):839-845.

25. Vandevoorde J, Verbanck S, Gijssels L, et al. Early detection of COPD: a case finding study in general practice. Respir Med. 2007;101(3): $525-530$.

26. Ulrik CS, Løkke A, Dahl R, et al. Early detection of COPD in general practice. Int J Chron Obstruct Pulmon Dis. 2011;6:123-127.

27. Siafakas NM, Vermeire P, Pride NB, et al. Optimal assessment and management of chronic obstructive pulmonary disease (COPD). The European Respiratory Society Task Force. Eur Respir J. 1995;8(8): 1398-1420.

28. Tashkin DP, Celli B, Decramer M, et al. Bronchodilator responsiveness in patients with COPD. Eur Respir J. 2008;31(4):742-750.

29. Reid DW, Soltani A, Johns DP, et al. Bronchodilator reversibility in Australian adults with chronic obstructive pulmonary disease. Intern Med J. 2003;33(12):572-577.

30. Albert P, Agusti A, Edwards L, et al. Bronchodilator responsiveness as a phenotypic characteristic of established chronic obstructive pulmonary disease. Thorax. 2012;67(8):701-708.

31. Calverley PM, Burge PS, Spencer S, Anderson JA, Jones PW. Bronchodilator reversibility testing in chronic obstructive pulmonary disease. Thorax. 2003;58(8):659-664.

32. Hanania NA, Sharafkhaneh A, Celli B, et al. Acute bronchodilator responsiveness and health outcomes in COPD patients in the UPLIFT trial. Respir Res. 2011;12:6.

33. From the Global Strategy for Asthma Management and Prevention, Global Initiative for Asthma (GINA). 2014. Available from: www. ginasthma.org. Accessed January 13, 2014.

34. Hanania NA, Celli BR, Donohue JF, Martin UJ. Bronchodilator reversibility in COPD. Chest. 2011;140(4):1055-1063.

35. Anthonisen NR, Lindgren PG, Tashkin DP, et al. Bronchodilator response in the Lung Health Study over 11 yrs. Eur Respir J. 2005;26(1): $45-51$ 


\section{Supplementary material}

Table SI List of definitions

Definitions
Airway obstruction
BD reversibility test
Corticosteroid reversibility test
COPD
GOLD severity of airway obstruction
GOLD I: mild
GOLD 2: moderate
GOLD 3: severe
GOLD 4: very severe
Asthma

$\mathrm{FEV}_{\text {, } / \mathrm{FVC} \text { ratio }<0.70}$

ERS/ATS recommendations: "Significant" BD response was defined as an increase in FEV, of minimum $0.200 \mathrm{~L}$ and $\mathrm{I} 2 \%$ of pre-BD FEV after administration of a short-acting $\beta_{2}$ agonist ${ }^{30}$ Six weeks of treatment with inhaled corticosteroid or 14 days of oral steroid followed by repeat spirometry. An increase in FEV, of $>0.200 \mathrm{~L}$ was considered a positive test Spirometric defined according to GOLD recommendations 2014: Post-BD FEV $/$ FVC ratio $<0.70^{16}$ $\mathrm{FEV}, \%$ predicted:

$\geq 80 \%$

$50 \% \leq \mathrm{FEV},<80 \%$

$30 \% \leq \mathrm{FEV}_{1}<50 \%$

$<30 \%$

Increase in $\mathrm{FEV}_{1}>0.500 \mathrm{~L}$ at the $\mathrm{BD}$ reversibility test or $>0.200-0.500 \mathrm{~L}$ with additional $0.200 \mathrm{~L}$ increase on the corticosteroid reversibility test

Abbreviations: ATS, American Thoracic Society; BD, bronchodilator; COPD, chronic obstructive pulmonary disease; ERS, European Respiratory Society; FEV ${ }_{1}$, forced expiratory volume in one second; FVC, forced vital capacity; GOLD, Global Initiative for Chronic Obstructive Lung Disease.

\section{Publish your work in this journal}

The International Journal of COPD is an international, peer-reviewed journal of therapeutics and pharmacology focusing on concise rapid reporting of clinical studies and reviews in COPD. Special focus is given to the pathophysiological processes underlying the disease, intervention programs, patient focused education, and self management protocols.

\section{Dovepress}

This journal is indexed on PubMed Central, MedLine and CAS. The manuscript management system is completely online and includes a very quick and fair peer-review system, which is all easy to use. Visit $\mathrm{http}: / /$ www.dovepress.com/testimonials.php to read real quotes from published authors. 